\title{
PROJETO HISTÓRIA E CULTURA AFROBRASILEIRA E AFRICANA NAS AULAS DE GEOGRAFIA DO ENSINO MÉDIO
}

\author{
Adriany de Ávila Melo Sampaio \\ LAGEPOP-IG-Universidade Federal de Uberlândia - UFU. \\ E-mail: adrianyavila@gmail.com \\ Rosana de Ávila Melo Silveira \\ Instituto Federal do Triângulo Mineiro - IFTM - Uberlândia. \\ E-mail: rosanasilveira@iftm.edu.br \\ Antônio Carlos Freire Sampaio \\ LAGEPOP-IG- Universidade Federal de Uberlândia - UFU. \\ E-mail: acfsampa@uol.com.br \\ Aluê Gomes da Silva \\ LAGEPOP-IG- Universidade Federal de Uberlândia - UFU. \\ E-mail: aluegomes@yahoo.com.br \\ Ana Flávia Borges de Oliveira \\ LAGEPOP-IG- Universidade Federal de Uberlândia - UFU. \\ E-mail: anaflaviaborges97@hotmail.com
}

\begin{abstract}
RESUMO
A exigência da "História e Cultura Afro-Brasileira e Indígena" trouxe para todos os cursos de formação de professores a responsabilidade em formar profissionais capazes de contribuir nesta temática. Apesar da lei ser do ano de 2003 ainda há muito a ser realizado para que essa questão seja um conteúdo comum nas escolas de Educação Básica. Uma das formas da Geografia contribuir com esse tema é começar a repensar a formação inicial do professor também como pesquisador, e de todo estudante como uma pessoa que pesquisa, que elabora e constrói conhecimento. Neste Projeto o Estudante do Ensino Médio teve a oportunidade de uma formação em pesquisa uma vez que o Objetivo Geral de Pesquisa foi a análise das possibilidades de inclusão da História e Cultura Afrobrasileira e Africana nos conteúdos de Geografia do Ensino Médio se colocando como estudante e pesquisador desta disciplina. Para diagnosticar as questões Étnico-raciais, especialmente sobre o cumprimento das leis federais 10639/03 e 11.645/08.
\end{abstract}

Palavras-chave: Lei federal 10.639/03. Lei federal 11.645/08. Estudante pesquisador. Livro didático

\section{INTRODUÇÃO}

Antes mesmo da Lei 10639/0, os PCN (BRASIL, 1997) traziam em seus Temas Transversais a Pluralidade Multicultural que reconhecia e valorizava a diversidade existente em nossa sociedade e buscava a superação das discriminações para que o Brasil fosse realmente um país democrático. Mas a Lei trouxe um peso muito maior para a discussão da questão. 
Constituindo-se, assim, como um tema delicado e complexo, nunca houve consenso em torno das teorias que buscaram responder "quem é o povo brasileiro?", consequentemente, "o que faz do Brazil, Brasil?". Um consenso, talvez, seja que toda problemática que compõe a questão étnico-racial gira em torno da ideia de miscigenação. Uma perspectiva bastante problemática quando pensada a partir da realidade brasileira, marcada pelo racismo e por uma história de escravização, expropriação e violência. (CIRQUEIRA; CORREA, 2012, p.02).

Os meios de comunicação apresentam grande número de informações, contudo de forma fragmentada e facilmente esquecível, e que a criança, o jovem e até mesmo o adulto, sozinhos nem sempre conseguem transformam essas informações em conhecimentos, sendo fundamental que o professor se apodere dos conhecimentos relativos à história e cultura afro-brasileira e dos povos indígenas brasileiros fazendo deles temas que permitam um melhor conhecimento de nosso país e de nós mesmos. Não é possível mais que esta questão fique omitida na Educação como um todo, pois

\footnotetext{
O desconhecimento das experiências de ser, viver, pensar e realizar de índios, de descendentes de africanos, de europeus, de asiáticos, faz com que ensinemos como se vivêssemos numa sociedade monocultural. Isto nos torna incapazes de corrigir a ilusão da democracia racial, de vencer determinações de sistema mundo centrado em cosmovisão representativa de uma única raiz étnico-racial. (SILVA, 2007, p.501).
}

O objetivo geral da Educação é a formação do cidadão; uma pessoa com direitos e deveres, e principalmente comprometida com as questões de sua época social. Por sua vez, o objetivo da Geografia como disciplina escolar é formar o cidadão capaz de compreender as relações entre a sociedade e a natureza, e como esta sociedade se organiza, como constrói, destrói e reconstrói o espaço que ocupa. O professor que irá contribuir para a formação deste cidadão se forma em Cursos de Graduação, especialmente as licenciaturas, áreas do conhecimento que permitem a formação inicial dos docentes.

O Curso de Graduação, considerado como curso de Formação Inicial é o principal momento de construção do conhecimento básico da área de estudo futuro profissional. Ele será sempre a maior referência, por isso quanto antes o estudante de licenciatura e futuro professor começar a analisar conteúdos pertinentes à sua área de atuação, a escola, melhor será sua prática. Neste projeto, começaremos a formação para a pesquisa com o Estudante do Ensino Médio.

Uma das questões atuais da formação para a cidadania é a obrigatoriedade da temática "História e Cultura Afro-Brasileira e Indígena", colocada pela Lei n 11.645, 
de 10 março de 2008, que alterou a Lei no 9.394, de 20 de dezembro de 1996, modificada pela Lei no 10.639, de 9 de janeiro de 2003, que estabelece as diretrizes e bases da educação nacional e a incluiu no currículo oficial da rede de ensino.

A exigência da temática "História e Cultura Afro-Brasileira e Indígena” trouxe para todos os cursos de formação de professores a responsabilidade por formar profissionais capazes de contribuir nesta temática, pois segundo a Lei 11645/08: "os conteúdos referentes à história e cultura afro-brasileira e dos povos indígenas brasileiros serão ministrados no âmbito de todo o currículo escolar" (BRASIL, 2008).

Para que a Geografia possa de fato contribuir para superar os preconceitos, este projeto acredita que, entre outras questões, precisamos começar a formação pesquisador o quanto antes, por isso a importância deste projeto ser desenvolvido por um estudante do Ensino Médio, e especialmente incentivado por uma Bolsa de Iniciação Científica BIC Júnior.

\footnotetext{
Ao assumirmos a educação étnico-racial de professores em formação inicial como questão central, reportamo-nos a um tema historicamente escamoteado por manobras discursivas da elite hegemônica brasileira (...). (OLIVEIRA; SILVA, 2017, p. 188).
}

O estudante deste Projeto analisou possibilidades de inclusão da História e Cultura Afrobrasileira e Africana nos conteúdos de Geografia do Ensino Médio. Assim, este Projeto tem como objetivo Geral: Analisar como os conteúdos de Geografia do Ensino Médio podem ensinar a História e Cultura Afro-brasileira e Africana. E como Objetivos Específicos: 1. Discutir as questões Étnico-raciais, especialmente sobre o cumprimento das leis federais 10639/03 e 11.645/08 na Escola; 2. Evidenciar as principais necessidades e potencialidades do Planejamento de Geografia do Ensino Médio para a execução das leis federais 10639/03 e a 11.645/08; 3. Organizar, em conjunto com a equipe do projeto, atividades de Formação Continuada sobre Ensinar e aprender Geografia a partir das Leis federais 10639/03 e a 11.645/08.

\section{POSSIBILIDADES DA GEOGRAFIA NO ENSINO MÉDIO}

Uma das funções da Geografia é refletir sobre como a sociedade se organiza, como ela ocupa o espaço em diferentes momentos históricos, e a questão dos povos africanos, afro-descendentes e indígenas faz parte do Espaço que a Geografia se propõe estudar. 


\begin{abstract}
A geografia é a ciência do território, e o território é o melhor instrumento de observação do que está acontecendo no espaço geográfico. Ela expõe a diversidade regional, as desigualdades espaciais, as potencialidades da natureza e a heterogeneidade da população. Essa é a área do conhecimento que tem o compromisso de tornar os lugares e suas dinâmicas mais compreensíveis, de dar explicações para as transformações territoriais e de apontar soluções para as incongruências e incompatibilidades espaciais. (ANJOS, 2005, p. 167-168).
\end{abstract}

Uma das tarefas do futuro profissional da licenciatura é escolher o Livro didático mais adequado para sua escola. Esta escolha é realizada a cada quatro anos, e o livro será usado pelos alunos durante três anos. O professor precisa ter em mente que o objetivo principal é o aprendizado. Especificamente, no caso da Geografia, o professor precisa estar atento às representações gráficas e cartográficas, e como elas interagem com os textos, de forma que proporcione uma ampliação dos conhecimentos espaciais, tanto do cotidiano dos estudantes como de lugares distantes, sobretudo na atualidade com o processo de globalização em curso. O livro didático de Geografia não pode apresentar-se como um conjunto sem nexos ou correlações, é preciso que os autores de livros didáticos descubram formas atraentes de tratar de assuntos relativos ao cotidiano dos alunos do ponto de vista espacial, sempre os relacionando com outras realidades.

Devido à grande extensão territorial do Brasil, as realidades e culturas são muito diferentes dificultando o professor utilizar o livro didático como instrumento auxiliar de sua reflexão geográfica com seus alunos, entretanto o professor precisa saber relacionar os conteúdos e as imagens do livro com as diferentes linguagens disponíveis e o cotidiano dos alunos, estabelecendo assim o diálogo e o confronto de ideias diferenciadas, fugindo da verdade absoluta, uma vez que nem a proposta de um livro, nem as ideias do professor, são infalíveis ou inquestionáveis.

Como o grande comprador de livros didáticos no país é o governo federal, as editoras têm procurado atender as avaliações feitas pelo Programa Nacional do Livro Didático - PNLD. Essa avaliação utiliza de critérios estabelecidos em Edital específico, e que se não forem contemplados pelo autor, excluem a obra da lista de compra do MEC. Entre os motivos de exclusão de obra inscrita no PNLD, diz respeito aos livros que apresentem preconceito ou induzam ao preconceito.

Os Editais do PNLD de 2013, 2014 e 2015 (livros para os Ensino Fundamental I, II e Ensino Médio), trouxeram com ênfase a questão da História e Cultura AfroBrasileira, Africana e Indígena, como preconizam as Leis Federais 10.639/03 e 11.645/08. Assim, é de se esperar que as obras inscritas nestes novos editais 
apresentem, minimamente, as questões etnicorraciais. Mas o mínimo exigido por lei ainda é pouco, porque o professor terá que ir, além disso, se realmente for trabalhar as questões étnico-raciais.

Segundo o Guia do PNLD de Geografia de 2007, já era previsto a preocupação com a não transmissão ou insinuação de preconceitos. O mesmo ocorreu com os Guias posteriores como no Guia PNLD de 2009 (BRASIL, 2009).

Mas, apesar das regras do PNLD ainda são poucos os Livros Didáticos que apresentam a cultura afro-brasileira e os povos indígenas como objeto de estudo em mais de um capítulo, e que recebem abordagens respeitosas, que valorizam suas organizações e saberes. Assim como a participação desses povos nos processos históricos que levaram à formação do espaço geográfico brasileiro. Também é raro mostrar a participação dos povos afrodescendentes e indígenas brasileiros em lutas e mobilização políticas pelos seus direitos, ou a atuação desses grupos em diferentes trabalhos e profissões valorizadas socialmente, o que prejudica a compreensão de como esses grupos étnicos culturais colaboraram com a construção sociocultural e econômica do Brasil.

A participação do negro e do indígena na formação do espaço geográfico brasileiro são abordadas raramente e em poucos capítulos do Livro Didático. A imagem do afrodescendente é pouco utilizada tanto em espaços profissionais como em espaços de poder, e assim como os indígenas, repassam imagens estereotipadas.

\footnotetext{
Negros e negras, no Brasil, desde que para essa terra foram trazidas à força as primeiras pessoas africanas para serem escravizadas, lutam pela vida, pela sua humanidade, por liberdade e, a partir da abolição do escravismo, pelos seus direitos de cidadania, através da defesa de políticas de inclusão racial. A exclusão de negros e negras no processo educacional é histórica. Foi muito longo o período de denúncias do movimento negro e de pesquisadores envolvidos com a temática em busca de uma educação não racista, que ainda não está consolidada. (NASCIMENTO, 2013, p.24).
}

A nação brasileira é formada basicamente por três grandes grupos étnico-raciais: o branco, o indígena e o negro, sendo que cada um tem uma história de origem diferenciada e apesar da miscigenação ainda há muito preconceito, principalmente em relação ao negro e ao índio. Esse preconceito, em muitos casos, é apresentado de forma sutil, podendo muitas vezes passar despercebido a ponto de surgirem afirmações de que no Brasil não há preconceito. 
Diferentemente dos indígenas que já habitavam o Brasil e dos brancos europeus que migraram para cá, os negros vieram para o Brasil de uma forma trágica, basta lembrar um pouco da história do Brasil, do tráfico humano de homens e mulheres da África, que foram perseguidos, presos e escravizados. Foram forçados a deixar suas famílias na África e transportados em navios em condições desumanas, sendo obrigados a trabalharem na plantação sob os mais terríveis e cruéis castigos.

Com o "fim da escravidão" em 1888 a situação do povo negro apenas mudou de paradigma, pois se antes era refém dos castigos agora teria que enfrentar a fome, o desemprego, a falta de abrigo e moradia, enfim, a miséria. Essa situação de precariedade fez do povo negro um grupo marginalizado na sociedade brasileira, fazendo com que fosse construída uma imagem totalmente negativa e consequentemente muito preconceituosa.

Considerando a questão indígena, há também muita omissão e desvalorização por parte dos livros, pois em sua maioria, os indígenas são retratados por meio de algumas poucas imagens, e quase nada de sua atualidade, muito menos de sua presença como cidadão brasileiro. Há ainda muito estereótipo veiculado, o que desinforma mais do que informa.

[As instituições] têm realizado progressos significativos na promoção da educação das relações étnico-raciais, porém, sinalizam necessidade de formação continuada de seus profissionais para que estes possam se qualificar ainda mais para a realização de ações pedagógicas. (LIMA; REGO, 2017, p. 189-190).

Pode-se afirmar que o preconceito no Brasil está sendo extinto, principalmente à força de lei, entretanto, há ainda um longo percurso até que a realidade nacional seja de valorização de todos, sem exceção.

A compreensão de todas as etnias de forma integrada à sociedade brasileira do ponto de vista da construção cultural e dos saberes ainda é veiculada de forma superficial, sendo bastante pontual a discussão sobre como vivem os indígenas atualmente. Os livros, em geral, não se preocupam em apresentar os seus saberes, limitando-se a algumas contribuições particulares. As imagens das etnias indígenas brasileiras aparecem de forma superficial e tipificada, quase sempre e somente na parte em que se comenta a diversidade cultural brasileira e dos afro-brasileiros. Não é ressaltada a participação destes grupos sociais em diferentes profissões e espaços de poder. 
A escola por meio dos professores, e especificamente a disciplina de Geografia, tem as condições necessárias para discutir a questão étnico-racial, no entanto, é preciso estar atento ao descaso e à marginalização, pois mesmo com as leis o preconceito pode estar nas entrelinhas, justamente pela omissão, contribuindo de forma acentuada para formarmos cidadãos incompletos.

\section{CONSIDERAÇÕES FINAIS}

Ao longo dos anos 2018 e 2019 realizamos duas etapas do Projeto, com a presença de quatro estudantes do Ensino Médio, que juntamente com estudantes de graduação, pós graduação, professores da UFU e também da rede pública estadual e municipal participaram semanalmente do Grupo de Estudos.

As discussões permearam as Leis Federais 10639/03 e 11.645/08 o que proporcionou muitos debates e construção de conhecimentos.

Para as atividades de Formação Continuada sobre Ensinar e aprender Geografia a partir das Leis federais 10639/03 e a 11.645/08 os estudantes participaram também de cursos de extensão sobre Geografia e Educação Étnico-racial, e de eventos acadêmicos.

\section{REFERÊNCIAS}

ANJOS; Rafael Sanzio Araújo dos. A África, a Educação Brasileira e a Geografia. In: Sales; Augusto dos Santos (Org.) Educação anti-racista: caminhos abertos pela Lei Federal nº 10.639/03. Brasília, 2005.p. 167-184.

BRASIL. Contribuições para Implementação da Lei 10.639/2003. Grupo de Trabalho Interministerial Instituído por Meio da Portaria Interministerial Mec/mj/seppir. No 605 de 20 de Maio de 2008. 58p.

BRASIL. Diretrizes Curriculares Nacionais para a Educação das Relações Étnicoraciais e para o Ensino de História e Cultura Afro-Brasileira e Africana. Parecer CNE/CP 3/2004, de 10 março de 2004.

BRASIL. Guia do Livro Didático - PNLD 2010 Geografia: Anos Iniciais do Ensino Fundamental. Brasília: MEC, 2009.

BRASIL. Lei No 10.639, de 9 de janeiro de 2003. D.O.U. de 10/01/2003. Brasília, 2003.

BRASIL. Lei No 11.645, de 10 de março de 2008. D.O.U. 11/03/2008. Brasília, 2008.

BRASIL. Parâmetros Curriculares Nacionais: Pluralidade Cultural, Orientação

Sexual. Secretaria de Educação Fundamental. Brasília: MEC/SEF, 1997. 164p. 
CIRQUEIRA, Diogo Marçal; CORREA, Gabriel Siqueira. A questão étnico-racial na Geografia Brasileira: um debate introdutório sobre a produção acadêmica nas pósgraduações. In: Anais... XII Coloquio Internacional de Geocrítica. Bogotá, 7 a 11 de mayo de 2012. 16p.

LIMA, Daniela da Costa Britto Pereira; REGO, Thabyta Lopes. Educação das Relações Étnico-Raciais na Educação Infantil. In: Revista Contemporânea de Educação, vol. 12, n. 23, jan./abr. de 2017.

NASCIMENTO, Alexandre do. Educação das relações étnico-raciais: elementos teóricos e metodológicos de uma prática de formação docente. In: Revista Magistro. Vol. 8 Num.2. p.19-27. 2013.

OLIVEIRA, Míria Gomes de; SILVA, Paulo Vinícius Baptista da. Educação ÉtnicoRacial e Formação Inicial de Professores: a recepção da Lei 10.639/03. In: Educação \& Realidade, Porto Alegre, v. 42, n. 1, p. 183-196, jan./mar. 2017.

SILVA, Petronilha Beatriz Gonçalves e. Aprender, ensinar e relações étnico-raciais no Brasil. In: Educação. Porto Alegre/RS, ano XXX, n. 3 (63), p. 489-506, set./dez. 2007. 